Contract No. and Disclaimer:

This manuscript has been authored by Savannah River Nuclear Solutions, LLC under Contract No. DE-AC09-08SR22470 with the U.S. Department of Energy. The United States Government retains and the publisher, by accepting this article for publication, acknowledges that the United States Government retains a non-exclusive, paid-up, irrevocable, worldwide license to publish or reproduce the published form of this work, or allow others to do so, for United States Government purposes. 


\title{
EFFECT OF IMPURITIES ON THE PERFORMANCE OF A Pd-Ag DIFFUSER
}

\author{
Gregg A. Morgan, Jr. \\ Savannah River National Laboratory, Aiken, SC 29808 \\ gregg.morgan@srnl.doe.gov
}

A commercially fabricated diffuser purchased from Johnson-Matthey, Inc. was evaluated for performance characterization testing at the Savannah River National Laboratory (SRNL). Different impurities are often present in the feed streams of the process diffusers, but the effect of these impurities on the diffuser performance is currently unknown. Various impurities were introduced into the feed stream of the diffuser at various levels ranging from $0.5 \%$ to $10 \%$ of the total flow in order to determine the effect that these impurities have on the permeation of hydrogen through the palladium-silver membrane. The introduction of various impurities into the feed stream of the diffuser had a minimal effect on the overall permeation of hydrogen through the $\mathrm{Pd}-\mathrm{Ag}$ membrane. Of the four impurities introduced into the feed stream, carbon monoxide (CO) was the only impurity that showed any evidence of causing a reduction in the amount of hydrogen permeating through the $\mathrm{Pd}-\mathrm{Ag}$ membrane. The hydrogen permeation returned to its baseline level after the $\mathrm{CO}$ was removed from the feed stream. There were no lasting effects of the CO exposure on the ability of the membrane to effectively separate hydrogen from the non-hydrogen species in the gas stream under the conditions tested.

\section{INTRODUCTION}

Diffusers, or permeators, constructed of palladium silver (Pd-Ag) alloy tubing wound into coils have been used for many years at SRS to separate hydrogen isotopes from other gases. ${ }^{1}$ Diffusers are often used in production operations without their performance characteristics completely understood or measured. There have been numerous investigations over the last several years to determine the effect that various impurities have on the permeation of hydrogen through the Pd-Ag membrane. ${ }^{2-5}$ Early studies have indicated that gases such as nitrogen $\left(\mathrm{N}_{2}\right)$, carbon monoxide (CO), carbon dioxide $\left(\mathrm{CO}_{2}\right)$, methane $\left(\mathrm{CH}_{4}\right)$, ammonia $\left(\mathrm{NH}_{3}\right)$ and water $\left(\mathrm{H}_{2} \mathrm{O}\right)$ do not impede the rate of hydrogen permeation through a $\mathrm{Pd}-\mathrm{Ag}$ membrane at temperatures above $300^{\circ} \mathrm{C}$. Recent studies suggest however that $\mathrm{CO}$ is capable of occupying the sites needed for $\mathrm{H}_{2}$ adsorption and dissociation on $\mathrm{Pd}$ membranes up to $400^{\circ} \mathrm{C} .^{6}$
The work presented here will examine the effect that various impurities $\left(\mathrm{CH}_{4}, \mathrm{CO}_{2}, \mathrm{CO}\right.$, and $\left.\mathrm{NH}_{3}\right)$ have on the permeation of hydrogen through the $\mathrm{Pd}-\mathrm{Ag}$ tubes of the diffuser. The effect of the impurities on the permeation of hydrogen was currently unknown for this diffuser configuration. The results presented here are specific to this particular diffuser configuration, but the trends observed can be extended to other configurations.

\section{EXPERIMENTAL}

A flow test manifold was assembled for diffuser testing. Diffuser tests were conducted in an "inside-out": configuration where the feed mixture was supplied to the inlet of an open-ended coil and the hydrogen permeated into the surrounding shell space of the diffuser. Additional details regarding the manifold and the diffuser have been previously published. ${ }^{7}$ The permeate stream was directed to the mass flow controllers for direct measurement of the permeate flow. The system was equipped with a Leybold Inficon TRRTT100 RGA for analysis of the gas compositions of the feed, bleed, and permeates streams. A schematic of the system is shown in Figure 1.

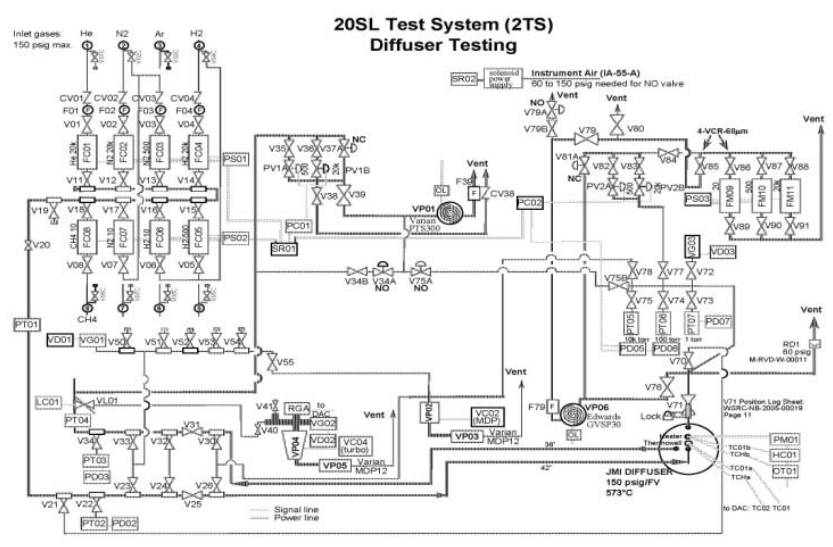

Figure 1: Schematic of Diffuser Test System

The gases used in these experiments included $\mathrm{N}_{2}$, $\mathrm{CH}_{4}, \mathrm{CO}_{2}, \mathrm{CO}$, and $\mathrm{NH}_{3}$ and were supplied to the diffuser by mass flow controllers ranging from $0.0169 \mathrm{~Pa} \mathrm{~m}^{3} / \mathrm{s}$ (10 
standard cubic centimeters per minute, sccm) to $33.78 \mathrm{~Pa}$ $\mathrm{m}^{3} / \mathrm{s}(20000 \mathrm{sccm})$. The nitrogen was supplied to the lab via a bulk liquid nitrogen tank. No measurement of the purity level of the $\mathrm{N}_{2}$ was made, but the manufacturer claims $>99.99 \%$ purity. The various impurity species used in this investigation were carbon dioxide with 1.00\% research grade krypton (Air Liquide); anhydrous ammonia (Specialty Gases of America, 99.99\% purity); carbon monoxide (Air Liquide, research grade, 99.999\%); and methane with $0.999 \%$ research argon (Air Liquide).

Feed compositions tested were a 50\% hydrogen and $50 \%$ nitrogen mixture with total flow rates ranging from $0.0169 \mathrm{~Pa} \mathrm{~m}^{3} / \mathrm{s}$ to $23.64 \mathrm{~Pa} \mathrm{~m}^{3} / \mathrm{s}$ (100 to $14,000 \mathrm{sccm}$ ). The various impurities were introduced into the feed stream at levels ranging from $0.5 \%$ of the total feed to $10 \%$ of the total feed. The various gas mixtures were flowed through the diffuser at each of the flow rates for sixty minutes prior to the collection of the data points. The diffuser was operated with a shell temperature of $400^{\circ} \mathrm{C}$, measured with a thermowell located in the shell space of the diffuser. All of the tests were conducted with the pressure inside the Pd-Ag tube maintained at 106657 $\mathrm{Pa}$ (800 torr) while the shell of the diffuser was evacuated to roughly $0.133 \mathrm{~Pa}\left(\sim 10^{-3}\right.$ torr). The pressure was controlled using a pressure transducer, which measured the feed stream pressure upstream of the diffuser.

\section{RESULTS AND DISCUSSION}

Experimental testing evaluated the effects of methane $\left(\mathrm{CH}_{4}\right)$, carbon dioxide $\left(\mathrm{CO}_{2}\right)$, carbon monoxide $(\mathrm{CO})$, and ammonia $\left(\mathrm{NH}_{3}\right)$ on the permeation of hydrogen through the palladium-silver membrane. The overall performance of the Pd-Ag diffuser was evaluated prior to the introduction of the impurities as well as after the introduction of the various impurities. The results of the experimental testing are typically plotted as the bleed flow rate as a function of the total feed flow rate. The bleed flow rate is determined from the difference of the total flow rate and the permeate flow rate. In addition, residual gas analyzer data of the feed and bleed stream was collected and evaluated.

\section{A. Methane $\left(\mathrm{CH}_{4}\right)$}

Methane was introduced into the feed stream at 2.0\% of the total feed flow and the results are shown in Figure 2. Experiments were conducted at increasing flow rates from $1.69 \mathrm{~Pa} \mathrm{~m}^{3} / \mathrm{s}$ to $20.27 \mathrm{~Pa} \mathrm{~m}^{3} / \mathrm{s}$ (1000 to $12000 \mathrm{sccm}$ ). Figure 2 shows the bleed versus the total feed rate curves without any methane in the system, in the presence of methane, and following the exposure to methane. There is no change in the permeation of hydrogen in the presence of or after $2.0 \%$ methane was present in the feed stream compared to the $\mathrm{H}_{2}$ permeation before the introduction of the methane.

RGA data (not shown here) did not yield any evidence of $\mathrm{CH}_{4}$ dissociation on the surface of the Pd-Ag tube. There was little change in the mass 15 and mass 16 signal of the analysis before the diffuser and after the diffuser, indicating that the $\mathrm{CH}_{4}$ was not dissociating on the surface.

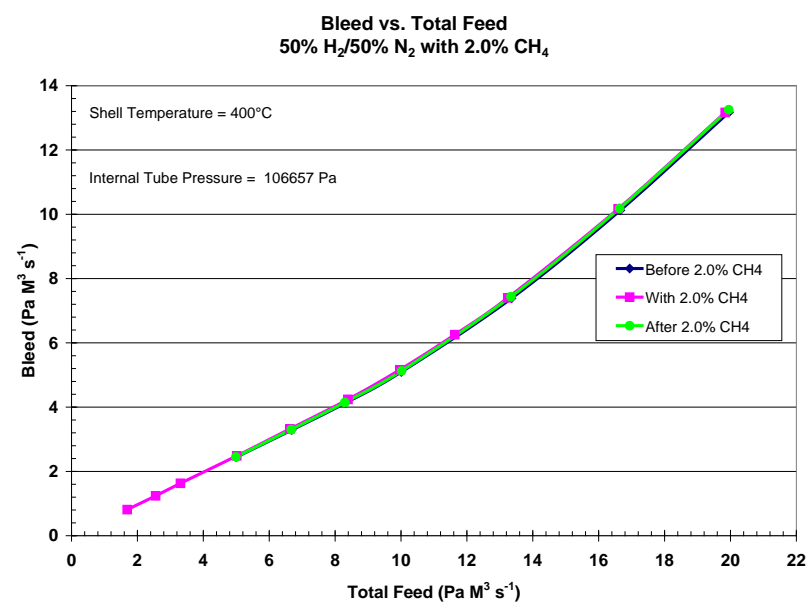

Figure 2: Plot of Bleed vs. Total Feed for $50 \% \mathrm{H}_{2} / 50 \% \mathrm{~N}_{2}$ with $2.0 \% \mathrm{CH}_{4}$

\section{B. Carbon Dioxide $\left(\mathrm{CO}_{2}\right)$}

Figure 3 shows the results of the testing that was completed with carbon dioxide present in the feed stream. Experiments were conducted with $2.0 \% \mathrm{CO}_{2}$ at increasing flow rates from $1.69 \mathrm{~Pa} \mathrm{~m}^{3} / \mathrm{s}$ to $20.27 \mathrm{~Pa} \mathrm{~m}^{3} / \mathrm{s}$ (1000 to $12000 \mathrm{sccm})$. These experiments yielded similar results to the previous tests with $\mathrm{CH}_{4}$ in that there was essentially little or no change in the permeation of hydrogen through the palladium-silver membrane of the diffuser following the introduction of the carbon dioxide.

An analytical evaluation of the gas composition of the bleed stream shows no evidence of $\mathrm{CO}_{2}$ dissociation on the surface of the Pd-Ag diffuser. When the gas was passed through the diffuser there was roughly equal increases in the intensity of the mass 44 and mass 12 signals. Dissociation of $\mathrm{CO}_{2}$ on the surface would be characterized by a decrease in the mass 44 signal and an increase in the mass 12 signal. 


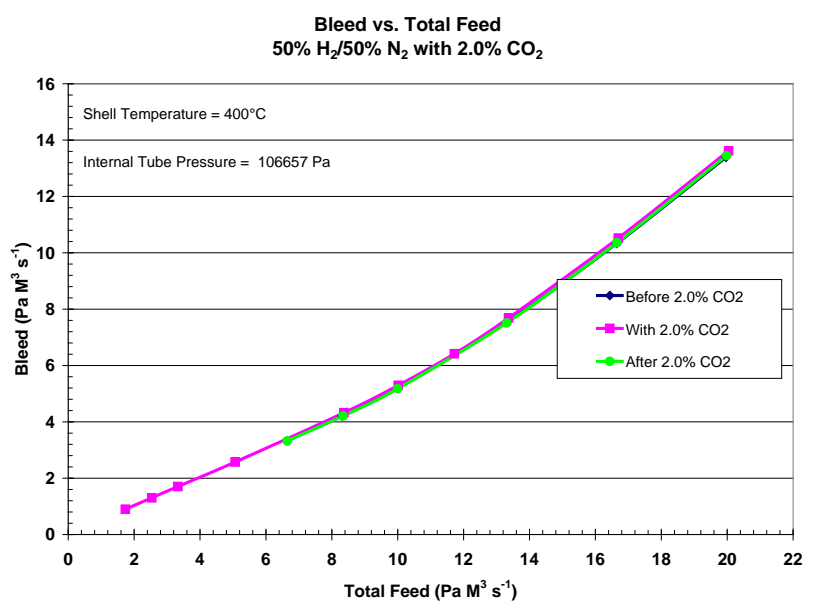

Figure 3: Plot of Bleed vs. Total Feed for $50 \% \mathrm{H}_{2} / 50 \% \mathrm{~N}_{2}$ with $2.0 \% \mathrm{CO}_{2}$

\section{B. Carbon Monoxide (CO)}

Figure 4 indicates the results when CO, a known catalytic poison, is introduced into the feed stream at $2.0 \%$ of the total feed rate. The hydrogen permeation following the exposure to $\mathrm{CO}$ seems to be roughly the same as the permeation prior to the exposure to $2.0 \%$. There was a noticeable difference in the permeation of hydrogen through the palladium-silver membrane in the presence of CO. As can be seen in Figure 4 (see inset), the amount of hydrogen permeating into the shell space seems to have decreased slightly in the presence of $\mathrm{CO}$ compared to the pre-exposure conditions. After the CO was removed from the feed stream, the hydrogen permeation returned to the pre-exposure levels.

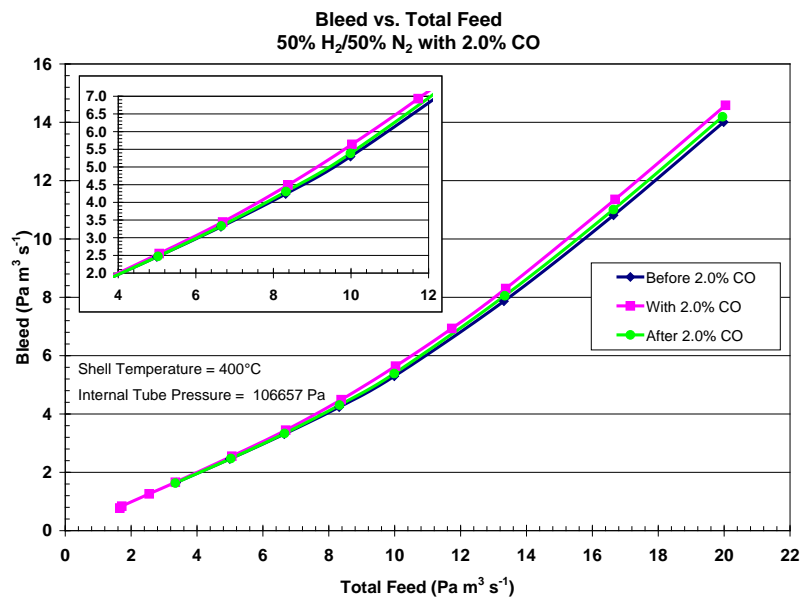

Figure 4: Plot of Bleed vs. Total Feed for $50 \% \mathrm{H}_{2} / 50 \% \mathrm{~N}_{2}$ with $2.0 \% \mathrm{CO}$

The results of the RGA analysis of the feed and bleed stream for a mixture of $50 \% \mathrm{H}_{2}$ and $50 \% \mathrm{~N}_{2}$ with $2.0 \%$
CO contained no evidence that $\mathrm{CO}$ was dissociating on the surface of the Pd-Ag membrane. When the feed gas mixture was introduced into the diffuser, there was a very slight increase in the signal for mass 12, but there was essentially no increase in the intensity of the mass 16 signal. If the $\mathrm{CO}$ was in fact dissociating on the surface an increase in the mass 16 signal would be expected.

\section{Ammonia $\left(\mathrm{NH}_{3}\right)$}

Ammonia was introduced into the feed stream at $0.5 \%$ of the total feed rate. The presence of $0.5 \% \mathrm{NH}_{3}$ in the feed stream had no effect on the permeation of $\mathrm{H}_{2}$ through the Pd-Ag membrane as shown in Figure 5. Based on additional data that was collected, it is expected that the presence of increased levels of ammonia in the feed stream will not effect the permeation of hydrogen through the membrane of the Pd-Ag diffuser.

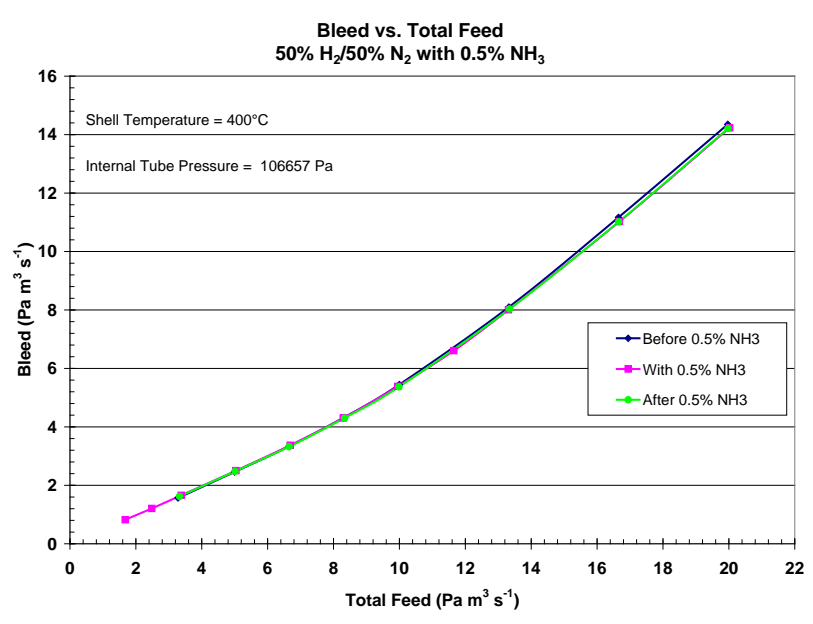

Figure 5: Plot of Bleed vs. Total Feed for $50 \% \mathrm{H}_{2} / 50 \% \mathrm{~N}_{2}$ with $0.5 \% \mathrm{NH}_{3}$

The RGA data (data not shown) shows that as the total feed flow rate is increased, there is a gradual increase in the signal for mass 17 as well as for mass 16 . indicating that the $\mathrm{NH}_{3}$ is not dissociating at the surface of the diffuser. The signals for mass 16 and mass 17 are the same intensity and therefore it can be concluded that the $\mathrm{NH}_{3}$ is not dissociating on the surface of the Pd-Ag membrane.

\section{E. Effect of Impurity Concentration}

A series of tests were run at $8.44 \mathrm{~Pa} \mathrm{~m}^{3} / \mathrm{s}$ (5000 $\mathrm{sccm}$ ) in which the percentage of impurity in the feed stream was increased from $0.1 \%$ to $10 \%$. Figure 6 shows the percentage of available $\mathrm{H}_{2}$ permeating versus the impurity level. The presence of ammonia and carbon dioxide at levels up to $10 \%$ does not have much impact on the overall permeation of hydrogen through the Pd-Ag 
membrane. In the case of ammonia, the amount of hydrogen that permeates through the membrane was measured to be greater than the amount of hydrogen that is originally present in the feed stream. This is most likely attributed to experimental error (i.e. drift in the mass flow controllers) as the permeation level is fairly constant even as the level of the impurity increases. If the $\mathrm{NH}_{3}$ was in fact dissociating at the surface, then the percentage of available hydrogen permeating would increase instead of remaining constant. As the level of $\mathrm{CO}_{2}$ increases in the feed stream there is very slight increase in the percentage of available hydrogen that permeates through the $\mathrm{Pd}-\mathrm{Ag}$ membrane. A more interesting result is the fact that as the level of $\mathrm{CO}$ increases in the feed stream there is a gradual decrease in the percentage of available hydrogen that is able to permeate through the Pd-Ag membrane. This slight loss in the permeation capability of the membrane in the presence of CO may be due to a blocking of available active sites. As indicated previously in Figure 4, there is no evidence of any significant change in the permeation capability after the exposure of the membrane to increasing levels of CO. Any blocking of the active sites of the membrane is only temporary and the permeation capability is restored following the removal of the CO.

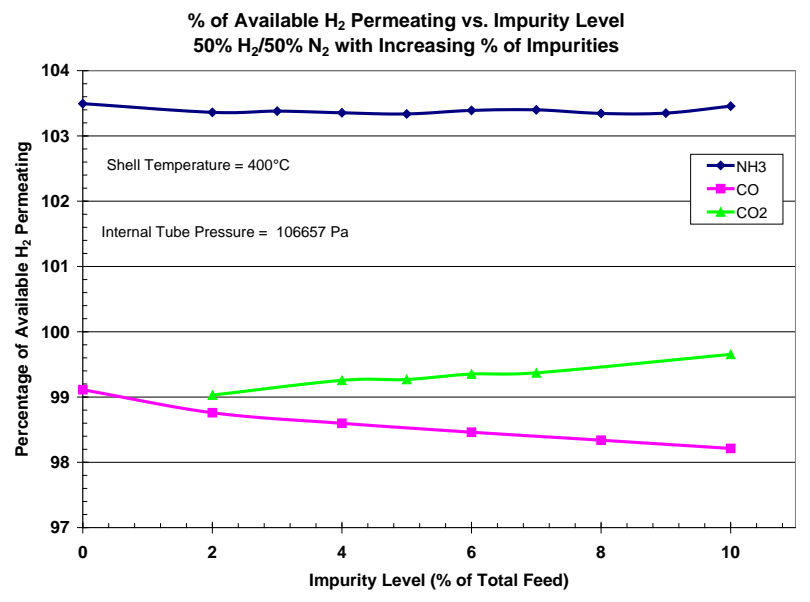

Figure 6: Permeate vs. Impurity level for $50 \% \mathrm{H}_{2} / 50 \% \mathrm{~N}_{2}$ with Increasing \% of Impurities

\section{CONCLUSIONS}

Even though the diffuser had previously been characterized to understand how the permeation of hydrogen is affected by varying the experimental parameters of pressure, temperature, and flow, there was still no clear understanding of what effect various impurities would have on the permeation of hydrogen through the Pd-Ag membrane. Methane, carbon dioxide, carbon monoxide, and ammonia were fed into the feed stream of the diffuser at varying levels from $0.5 \%$ to $10 \%$ of the total feed flow rate. The presence of the various impurities to the levels tested does not appear to have a significant effect on the permeation of hydrogen through the Pd-Ag membrane. In all cases the permeation of hydrogen was the same prior to the introduction of the impurities as it was following the exposure to the various impurities. The only impurity that showed potential to impede the permeation of hydrogen through the $\mathrm{Pd}-\mathrm{Ag}$ membrane was carbon monoxide, CO. When $\mathrm{CO}$ was introduced into the feed stream at $10 \%$ of the total feed, there was a decrease of roughly $1 \%$ in the percentage of available hydrogen that was permeating through the membrane. This loss in hydrogen permeation was only temporary and full hydrogen permeability was restored after the $\mathrm{CO}$ was removed from the feed stream.

\section{ACKNOWLEDGMENTS}

The author would like to gratefully acknowledge James Klein and Jody Dye for their support of this work. This manuscript has been authored by Savannah River Nuclear Solutions, LLC under Contract No. DEAC0908SR22470 with the U.S. Department of Energy. The United States Government retains and the publisher, by accepting this article for publication, acknowledges that the United States Government retains a non-exclusive, paid-up, irrevocable, worldwide license to publish or reproduce the published form of this work, or allow others to do so, for United States Government purposes.

\section{REFERENCES}

1. E. A. Clark, D. A. Dauchess, L. K. Heung, R. L. Rabun, and T. Motyka, Fusion Technol. 28, 566 (1995).

2. S. Welte, G. Ana, I. Cristescu, L. Dörr, B. Kuntz, J. Konrad, and R. Michling, Fus. Eng. Des. 84, 1969 (2009).

3. H. Li, A. Goldbach, W. Li, and H. Xu, J. Memb. Sci. 299, 130 (2007).

4. F. C. Gielens, R. J. J. Knibbeler, P. F. J. Duysinx, H. D. Tong, M. A. G. Vorstman, J. T. F. Keurentjes, J. Memb. Sci. 279, 176 (2006).

5. F. Gallucci, F. Chiaravalloti, S. Tosti, E. Drioli, and A. Basile, Int. J. Hydrogen Energ. 32,1837 (2007).

6. K. Hou and R. Hughes, J. Memb. Sci. 206, 119 (2002).

7. P. J. Foster, J. E. Klein, H. T. Sessions, and G. A. Morgan, Fus. Sci. Tech. 54, 591 (2008). 